Article

\title{
Bone Metabolism Analytes as Biomarkers of Pre-Frailty and Cardiovascular Disease Risk in Females
}

Kevin F. Boreskie 1,2,3, Christopher J. Oldfield ${ }^{1,2}$, Liam A. Thompson 1,2, Teri L. Moffatt ${ }^{1,2}$, Brett M. Hiebert ${ }^{4}$, Rakesh C. Arora ${ }^{2,5}$, Todd A. Duhamel 1,2,*

1 Faculty of Kinesiology and Recreation Management, University of Manitoba, Winnipeg, Manitoba R2H 2N2, Canada

2 Institute of Cardiovascular Sciences, St. Boniface Hospital Albrechtsen Research Centre, Winnipeg, Manitoba R2H 2A6, Canada

3 Max Rady College of Medicine, Rady Faculty of Health Sciences, University of Manitoba, Winnipeg, Manitoba R3E 0W2, Canada

4 Cardiac Sciences Program, Winnipeg Regional Health Authority, Winnipeg, Manitoba R2H 2A6, Canada

5 Department of Surgery, Max Rady College of Medicine, Rady Faculty of Health Sciences, University of Manitoba, Winnipeg, Manitoba R3E 0W2, Canada

* Correspondence: Todd A. Duhamel, Email: tduhamel@sbrc.ca; Tel.: +1-204-235-3589.

\section{ABSTRACT}

Background: Frailty and cardiovascular disease (CVD) share common pathophysiology in their progression. Declines in bone health often occur concomitantly with frailty and CVD. Therefore, analytes of bone metabolism may be useful biomarkers of pre-frailty and CVD risk. The aim of this study was to identify the effects of pre-frailty and CVD risk on the systemic concentrations of bone metabolism and inflammatory analytes in middle-aged and older females.

Method: This case-control study is a secondary analysis of data from 1030 females with no self-reported history of CVD. Frailty was measured using the Fried Criteria, and females were stratified into low and elevated CVD risk using the Framingham risk score. Greedy matching with pre-frailty as

\section{G Open Access}

Received: 12 December 2019 Accepted: 15 October 2020 Published: 21 October 2020

Copyright $(02020$ by the author(s). Licensee Hapres, London, United Kingdom. This is an open access article distributed under the terms and conditions of Creative Commons Attribution 4.0 International License. the exposure variable identified 26 matched pairs in the low and elevated CVD risk groups for a total of 104 females. Factorial ANOVA compared differences in the log transformed concentrations of 15 bone metabolism analytes based on pre-frailty status, CVD risk, and the interaction.

Results: Differences in the systemic concentrations of IL-6 (5.25 \pm 14.30 vs $1.35 \pm 1.74 \mathrm{pg} / \mathrm{mL}, p=0.001)$, TNFa $(1.41 \pm 1.83$ vs $0.89 \pm 0.40 \mathrm{pg} / \mathrm{mL}, p=$ $0.06)$, and leptin ( $12628.48 \pm 10472.90$ vs $7562.96 \pm 4972.25 \mathrm{pg} / \mathrm{mL}, p=0.023)$ were found in elevated CVD risk status compared to low. No differences in the concentrations of bone metabolism analytes were found based on prefrailty status, nor were any interaction effects.

Conclusion: Differences were found in the concentrations of cytokines involved in bone metabolism based on CVD risk; however, no differences 
were found based on pre-frailty status. IL-6, TNFa, and leptin may act as biomarkers of CVD risk, but this study does not support the use of the examined analytes involved in bone metabolism as biomarkers of pre-frailty.

KEYWORDS: frailty; cardiovascular disease; bone; bone metabolism analytes; biomarkers; females; aging

\section{ABBREVIATIONS}

CVD, cardiovascular disease; FRS, Framingham risk score; PHIN; Personal Health Identification Number; FC, Fried Criteria; HDL, high-density lipoprotein; ACTH; adrenocorticotropic hormone; DKK1, Dickkopf WNT signaling pathway inhibitor 1; IL-6, interleukin-6; TNFa, tumor necrosis factor $\alpha$; OPG, osteoprotegrin; OC, osteocalcin; OPN, osteopontin; IL-1 $\beta$, interleukin$1 \beta$; PTH, parathyroid hormone; FGF23, fibroblast growth factor 23

\section{INTRODUCTION}

The population of Canada is aging rapidly. Currently, $17 \%$ of the population is 65 and older [1], and this proportion is expected to reach $25 \%$ by 2036 [2]. From a public health perspective, this is likely to result in increasing prevalence of both frailty [3] and cardiovascular disease (CVD) [4] as the presence of these conditions is associated with age.

Frailty is characterized by a state of increased vulnerability to health stressors resulting from the dysregulation of multiple physiological systems [5]. This leads to a reduction in physiological reserve and an impaired ability to respond to adverse health events [6]. Pre-frailty is an intermediary stage preceding frailty that increases risk of frailty progression [6]. Individuals who are pre-frail are able to respond to health stressors [7], but are still at increased risk for disability, mortality, and morbidities, including CVD [6,8].

Frailty and CVD share similar risk factors and pathophysiological progression [9]. Sarcopenia and osteoporosis, as well as chronic inflammation [10] are often associated with both conditions. As a result, the presence of frailty and CVD are thought to exacerbate each other [11]. Recently, large pooled data sets have identified that frail individuals are at increased risk for CVD [12,13] and this increased risk is apparent in the earlier pre-frail stage [13-15]. This relationship is also bidirectional as individuals with a high CVD risk had an increased risk for incident frailty over a 4 year period (OR 2.15; 95\% CI 1.68-2.75) [16].

Biomarkers of both frailty and CVD are beginning to be examined with the goal of accurately identifying at-risk individuals earlier in downward health trajectory [17,18]. For example, blood-based biomarkers of inflammation have been studied as biomarkers of frailty in the youngerold and the very-old [19]. Given the related pathophysiology of frailty and CVD $[9,20]$, these conditions may share common biomarkers. 
Bone and muscle are both highly dynamic organs which secrete cytokines that act throughout the body [21-24]. The cross-talk between bone and muscle is receiving increased attention as it may have a role in health maintenance and decline [24-25]. Dysregulation in bone-muscle cross-talk can influence the progression of osteoporosis and sarcopenia [26] conditions often seen in frailty [27,28]. Pre-frail and frail individuals are at increased risk for osteoporotic fracture [29,30] and have been shown to present with reduced bone health [31,32]. Bone and cardiovascular health are also suggested to be linked, since reduced bone health is associated with increased risk for CVD, and vice versa [33,34], potentially implicating this same dysregulated cross-talk in CVD progression. Specifically, females who are post-menopause may be at increased risk for frailty-related reductions in bone and cardiovascular health, as hormonal changes post-menopause increase risk for both osteoporosis and CVD [35,36]. Bone metabolism analytes have previously been measured in the systemic circulation as a means of assessing bone health [22,37]. Given the relevance of bone metabolism and bone-muscle cross-talk to frailty characteristics and cardiovascular health, it is possible that these analytes may act as biomarkers of frailty and CVD.

The objective of this study was to identify the main and interaction effects of pre-frailty and CVD risk on the systemic concentrations of bone metabolism and inflammatory analytes in middle-aged and older females. Reduced bone health can occur concomitantly with frailty and CVD; therefore, bone metabolism analytes may be useful biomarkers of prefrailty and CVD risk. The identification of biomarkers in the early prefrailty stage could allow for easier detection and tracking of frailty progression [28].

\section{MATERIALS AND METHODS}

\section{Study Design}

The Strengthening the Reporting of Observational Studies in Epidemiology (STROBE) Statement guidelines for case-control studies were adhered to in the development of this manuscript [38]. This case-control study was a secondary analysis of data previously collected from an observational cohort study [39] approved by the University of Manitoba Health Research Ethics Board on September 29, 2014 (H2014:224) and the St-Boniface Hospital Research Review Committee on March 13, 2015 (RRC/2014/1417). The initial study examined the sensitivity and specificity of novel CVD risk assessment methods for predicting CVD events, such as the standardized Fried Criteria (FC) [40] and the Rasmussen Disease Score [41], as compared to established approaches, such as the Framingham Risk Score (FRS) [42].

\section{Participants}

The initial observational cohort study was conducted in Winnipeg, Manitoba, Canada and recruited 1030 females using radio and media ads. 
Participants were included if they were a female aged 55 years or older with no previous self-reported CVD, had a Personal Health Information Number (PHIN), and if informed consent was obtained. Participants were excluded if they had been previously hospitalized for CVD, as described in the protocol paper [40]. Propensity matching with pre-frailty as the exposure variable was then used to identify a top set of 26 matched pairs in the low and elevated CVD risk groups for a total of 104 females to better control for potential confounding variables (Figure 1).

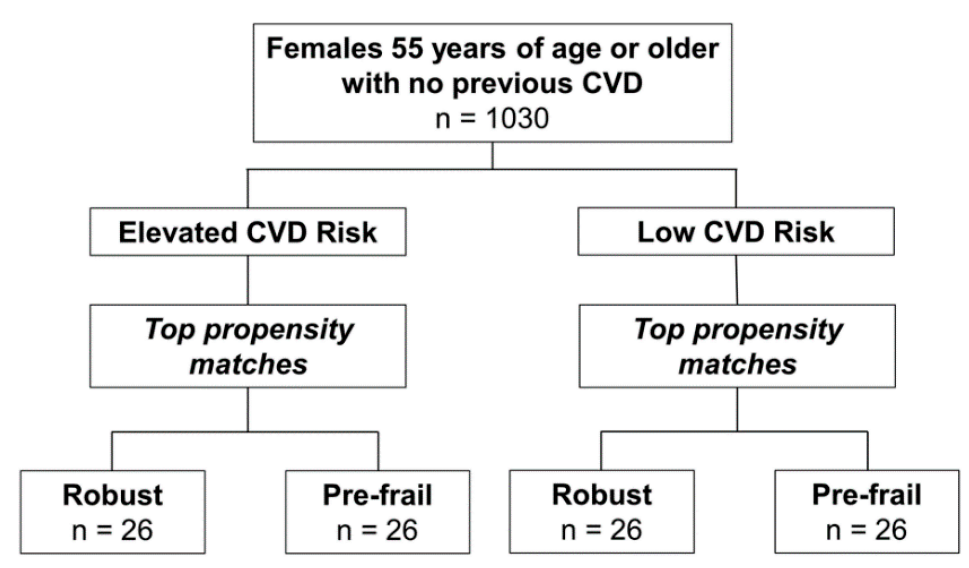

Figure 1. Study Flow Diagram.

\section{Assessments}

The FC was used to assess the frailty phenotype [6]. The FC assesses the presence of five criteria: (1) low physical activity levels; (2) slow walking speed; (3) muscle weakness (grip strength); (4) self-reported exhaustion; and (5) unintentional weight loss. Frailty status is determined using the number of criteria present (i.e., $0=$ robust, $1-2=$ pre-frail, $\geq 3=$ frail). The cut-offs demarcating the presence or absence of the criteria were based on those of Fried et al [6].

Participants were instructed to fast for $12 \mathrm{~h}$ pre-appointment. Fasted blood samples were collected from all 1030 females. Immediately following sample collection, blood was centrifuged at 2000× $\mathrm{g}$ for $10 \mathrm{~min}$ at $4{ }^{\circ} \mathrm{C}$. Plasma was then aliquoted into microcentrifuge tubes and stored at $-80{ }^{\circ} \mathrm{C}$ for future analyses.

The FRS was determined based on the model of D'Agostino et al. [42]. High-density lipoprotein (HDL) and total cholesterol were measured using the collected plasma. Resting blood pressure was measured in a supine position, following 10 minutes of rest, in a calm environment at room temperature. Resting blood pressure was measured using the HD/PulseWave ${ }^{\mathrm{TM}}$ CR-2000 Research CardioVascular Profiling System (Hypertension Diagnostics, Minneapolis, MN, USA). Participant sex, age, smoking status, diabetes status, and blood pressure treatment status were collected from participant questionnaires.

The systemic concentrations of bone metabolism analytes were measured with a EMD Millipore MILLIPLEX ${ }^{\circledR}$ Map Human Bone Magnetic 
Bead Panel-Bone Metabolism Multiplex Assay (EMD Millipore, Burlington, MA, USA) [43]. This multiplex assay allows for the concurrent quantification of adrenocorticotropic hormone (ACTH), Dickkopf WNT signaling pathway inhibitor 1 (DKK1), interleukin-6 (IL-6), insulin, tumor necrosis factor a (TNFa), leptin, osteoprotegrin (OPG), osteocalcin (OC), osteopontin (OPN), interleukin-1 $\beta$ (IL-1 $\beta$ ), parathyroid hormone (PTH), and fibroblast growth factor 23 (FGF23). These analytes were selected due to their roles in bone metabolism, amongst others. Plasma samples used in the analysis of the analytes were collected simultaneously as the plasma samples used in the FRS analysis.

\section{Statistical Analysis}

Participants were classified as low CVD risk (FRS $<10 \%$ ) or elevated CVD risk (FRS $\geq 10 \%$ ). Propensity scores based on a greedy match were calculated for the low and elevated CVD risk participants with the exposure variable of pre-frailty status, creating a case-control design with four groups: (1) Low FRS-Robust; (2) Elevated FRS-Robust; (3) Low FRS-Pre-frail, and; (4) Elevated FRS-Pre-frail. Propensity scores matched females for age, body mass index, continuous FRS, smoking status, and the number of currently prescribed medications. The analyte concentrations were log transformed to adjust for skewness and reduce variability in the data set. Factorial ANOVA compared the main and interaction effects of pre-frailty and CVD risk on the logtransformed systemic plasma concentration of 12 bone metabolism analytes. A Tukey post-hoc test was used to compare means where significant difference ( $p$-value $\leq 0.05$ ) was found. The study was powered using the concentration of the inflammatory cytokine IL- 6 from a similarly aged cohort [44] (distribution of $9.5 \pm 2.5 \mathrm{pg} / \mathrm{mL}$ (Mean \pm SD)), a total sample size of 80 (20 in each group) was calculated to detect a $25 \%$ difference between groups $(80 \%$ power; two-tailed alpha $=0.05)$. All statistical calculations were made using SPSS version 26 (IBM Corporation, Armonk, NY, USA).

\section{RESULTS}

\section{Descriptive Data}

Characteristics of the low and elevated CVD risk propensity matched groups were similar (Table 1). Mean age was lower in the robust group as compared to the pre-frail group in females of low CVD risk ( $62.92 \pm 4.89$ vs $65.58 \pm 7.10$ years, $p=0.02$ ). Differences were found in the prevalence of post-secondary education (22 (84.6\%) vs $15(57.7 \%), p=0.03)$, HDL cholesterol (1.63 \pm 0.43 vs $1.88 \pm 0.61 \mathrm{mmol}, p=0.04)$ and small artery compliance $(3.80 \pm 2.44$ vs $2.62 \pm 1.13 \mathrm{~mL} / \mathrm{mmHg} \times 10, p=0.01)$ between females who were robust and females who were pre-frail in the elevated CVD risk group. All females were post-menopause. 
Table 1. Characteristics of participants by CVD risk and frailty status.

\begin{tabular}{|c|c|c|c|c|}
\hline \multirow{24}{*}{ 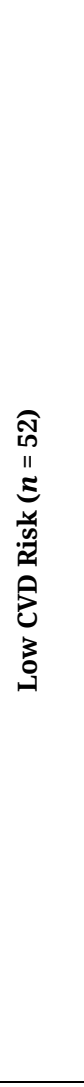 } & Characteristics & Robust $(n=26)$ & Pre-frail $(n=26)$ & $p$-value \\
\hline & Age (years) & $62.92 \pm 4.89$ & $65.58 \pm 7.10$ & 0.02 \\
\hline & BMI $\left(\mathrm{kg} / \mathrm{m}^{2}\right)$ & $25.44 \pm 4.14$ & $24.92 \pm 3.39$ & 0.53 \\
\hline & Post-secondary education (\% yes) & $21(80.8 \%)$ & $18(69.2 \%)$ & 0.34 \\
\hline & Ex/Current smoker (\% yes) & $7(26.9 \%)$ & $10(38.5 \%)$ & 0.38 \\
\hline & FRS (\%) & $6.44 \pm 2.12$ & $6.92 \pm 1.98$ & 0.58 \\
\hline & Fried frailty score & $0 \pm 0$ & $1.15 \pm 0.37$ & $<0.001$ \\
\hline & Medication(s) \# & $0.42 \pm 0.70$ & $0.54 \pm 0.81$ & 0.50 \\
\hline & Hypertension medication(s) (n) & $1(0.04 \%)$ & $5(19.2 \%)$ & 0.08 \\
\hline & Diabetes medication(s) (n) & $0(0 \%)$ & $0(0 \%)$ & - \\
\hline & Lipid medication(s) (n) & $5(19.2 \%)$ & $4(15.4 \%)$ & 0.71 \\
\hline & HDL cholesterol (mmol/L) & $1.92 \pm 0.53$ & $2.06 \pm 0.44$ & 0.36 \\
\hline & LDL cholesterol (mmol/L) & $3.48 \pm 0.67$ & $3.62 \pm 0.95$ & 0.07 \\
\hline & Total cholesterol (mmol/L) & $5.46 \pm 0.75$ & $5.74 \pm 1.00$ & 0.07 \\
\hline & Triglycerides (mmol/L) & $1.13 \pm 0.65$ & $1.06 \pm 0.40$ & 0.10 \\
\hline & Blood glucose (mmol/L) & $5.49 \pm 0.72$ & $5.28 \pm 0.52$ & 0.16 \\
\hline & Systolic blood pressure (mmHg) & $124.15 \pm 14.46$ & $122.65 \pm 10.93$ & 0.64 \\
\hline & Diastolic blood pressure (mmHg) & $70.35 \pm 9.85$ & $69.04 \pm 8.05$ & 0.39 \\
\hline & Small artery compliance $(\mathrm{mL} / \mathrm{mmHgx} 10)$ & $4.10 \pm 3.17$ & $4.52 \pm 2.80$ & 0.96 \\
\hline & Large artery compliance (mL/mmHgx10) & $12.41 \pm 4.23$ & $12.54 \pm 4.48$ & 0.58 \\
\hline & Grip strength (kg) & $25.73 \pm 2.74$ & $23.27 \pm 6.15$ & $<0.001$ \\
\hline & Walking speed (sec) & $3.84 \pm 0.53$ & $4.15 \pm 0.67$ & 0.49 \\
\hline & 6MWT (m) & $580.11 \pm 62.97$ & $548.27 \pm 73.09$ & 0.19 \\
\hline & Total MVPA/week (mins) & $613.20 \pm 2156.80$ & $313.18 \pm 346.41$ & 0.36 \\
\hline \multirow{24}{*}{ 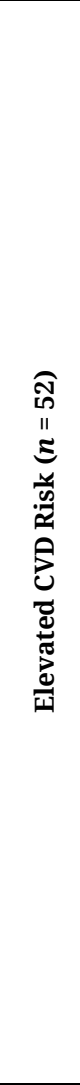 } & $\begin{array}{r}\text { Characteristics } \\
\end{array}$ & Robust $(n=26)$ & Pre-frail $(n=26)$ & $p$-value \\
\hline & Age (years) & $67.92 \pm 6.91$ & $69.54 \pm 5.23$ & 0.09 \\
\hline & BMI $\left(\mathrm{kg} / \mathrm{m}^{2}\right)$ & $28.29 \pm 3.67$ & $27.01 \pm 4.74$ & 0.08 \\
\hline & Post-secondary education (\% yes) & $22(84.6 \%)$ & $15(57.7 \%)$ & 0.03 \\
\hline & Ex/Current smoker (\% yes) & $12(46.2 \%)$ & $13(50.0 \%)$ & 0.78 \\
\hline & FRS (\%) & $16.51 \pm 5.88$ & $16.29 \pm 4.36$ & 0.29 \\
\hline & Fried frailty score & $0 \pm 0$ & $1.15 \pm 0.37$ & $<0.001$ \\
\hline & Medication(s) \# & $1.31 \pm 1.38$ & $1.54 \pm 1.39$ & 0.95 \\
\hline & Hypertension medication(s) (n) & $15(57.7 \%)$ & $16(61.5 \%)$ & 0.78 \\
\hline & Diabetes medication(s) (n) & $3(11.5 \%)$ & $4(15.4 \%)$ & 0.69 \\
\hline & Lipid medication(s) (n) & $5(19.2 \%)$ & $7(26.9 \%)$ & 0.51 \\
\hline & HDL cholesterol (mmol/L) & $1.63 \pm 0.43$ & $1.88 \pm 0.61$ & 0.04 \\
\hline & LDL cholesterol (mmol/L) & $3.91 \pm 0.80$ & $3.64 \pm 1.19$ & 0.23 \\
\hline & Total cholesterol (mmol/L) & $5.84 \pm 0.84$ & $5.73 \pm 1.26$ & 0.26 \\
\hline & Triglycerides $(\mathrm{mmol} / \mathrm{L})$ & $1.60 \pm 0.71$ & $1.23 \pm 0.56$ & 0.16 \\
\hline & Blood glucose $(\mathrm{mmol} / \mathrm{L})$ & $6.29 \pm 2.39$ & $6.09 \pm 1.74$ & 0.61 \\
\hline & Systolic blood pressure (mmHg) & $143.65 \pm 15.51$ & $146.27 \pm 10.12$ & 0.15 \\
\hline & Diastolic blood pressure (mmHg) & $76.50 \pm 7.75$ & $77.73 \pm 6.66$ & 0.84 \\
\hline & Small artery compliance (mL/mmHgx10) & $3.80 \pm 2.44$ & $2.62 \pm 1.13$ & 0.01 \\
\hline & Large artery compliance (mL/mmHgx10) & $10.63 \pm 3.04$ & $9.85 \pm 2.71$ & 0.50 \\
\hline & Grip strength $(\mathrm{kg})$ & $25.23 \pm 3.54$ & $21.62 \pm 6.46$ & 0.03 \\
\hline & Walking speed (sec) & $4.20 \pm 0.58$ & $4.48 \pm 0.96$ & 0.34 \\
\hline & $6 \mathrm{MWT}(\mathrm{m})$ & $527.31 \pm 59.20$ & $509.79 \pm 62.99$ & 0.22 \\
\hline & Total MVPA/week (mins) & $339.96 \pm 391.82$ & $201.60 \pm 266.50$ & 0.87 \\
\hline
\end{tabular}

Continuous variables expressed as mean \pm standard deviation and compared using $T$-test. CVD, cardiovascular disease; BMI, body mass index; FRS, Framingham Risk Score; 6MWT, 6-minute walk test; MVPA, moderate-to-vigorous physical activity. 


\section{Main Results}

The main effects for pre-frailty and CVD risk status and their interaction effects are found in Table 2. ACTH and PTH were not included in the final analysis as concentrations in the majority of the samples measured below detectable limits for the assay. Significantly higher concentrations were present in females of elevated CVD risk, as compared to those of low CVD risk for IL-6 ( $5.25 \pm 14.30$ vs $1.35 \pm 1.74 \mathrm{pg} / \mathrm{mL}, p=0.001$ ), TNFa (1.41 \pm 1.83 vs $0.89 \pm 0.40 \mathrm{pg} / \mathrm{mL}, p=0.006)$, and leptin (12628.48 \pm 10472.90 vs $7562.96 \pm 4972.25 \mathrm{pg} / \mathrm{mL}, p=0.023$ ). No differences in the concentrations of bone metabolism analytes were found based on prefrailty status. No interaction effects between pre-frailty status and CVD risk were found.

Table 2. Concentrations of Systemic Bone Metabolism Analytes by Frailty and CVD Risk.

\begin{tabular}{|c|c|c|c|c|c|}
\hline $\begin{array}{c}\text { Biomarker } \\
\text { (pg/mL) }\end{array}$ & $\begin{array}{l}\text { Robust } \\
(n=52)\end{array}$ & $\begin{array}{l}\text { Pre-frail } \\
(n=52)\end{array}$ & $\begin{array}{c}\text { Main Effect of } \\
\text { Pre-frailty } \\
(p \text {-value }) \neq\end{array}$ & $\begin{array}{c}\text { Main Effect of } \\
\text { CVD Risk } \\
(p \text {-value }) \neq\end{array}$ & $\begin{array}{c}\text { Interaction Effect } \\
(p \text {-value }) \neq\end{array}$ \\
\hline \multicolumn{6}{|l|}{ DKK1 } \\
\hline Low CVD Risk & $\begin{array}{l}156.34 \\
(40.27) \\
\end{array}$ & $\begin{array}{l}164.00 \\
(69.01) \\
\end{array}$ & \multirow{2}{*}{0.778} & \multirow{2}{*}{0.138} & \multirow{2}{*}{0.944} \\
\hline $\begin{array}{l}\text { Elevated CVD } \\
\text { Risk }\end{array}$ & $\begin{array}{l}145.61 \\
(53.28) \\
\end{array}$ & $\begin{array}{l}147.97 \\
(52.20) \\
\end{array}$ & & & \\
\hline \multicolumn{6}{|l|}{ IL-6 } \\
\hline Low CVD Risk & $1.27(1.71)$ & $1.43(1.80)$ & \multirow[b]{2}{*}{0.183} & \multirow[b]{2}{*}{0.001} & \multirow[b]{2}{*}{0.476} \\
\hline $\begin{array}{l}\text { Elevated CVD } \\
\text { Risk }\end{array}$ & $5.34(17.99)$ & $5.17(9.66)$ & & & \\
\hline \multicolumn{6}{|l|}{ Insulin } \\
\hline Low CVD Risk & $\begin{array}{r}346.39 \\
(281.18) \\
\end{array}$ & $\begin{array}{r}274.54 \\
(227.39) \\
\end{array}$ & \multirow{2}{*}{0.173} & \multirow{2}{*}{0.228} & \multirow{2}{*}{0.942} \\
\hline $\begin{array}{l}\text { Elevated CVD } \\
\text { Risk }\end{array}$ & $\begin{array}{r}457.90 \\
(581.96) \\
\end{array}$ & $\begin{array}{c}358.42 \\
(324.19) \\
\end{array}$ & & & \\
\hline \multicolumn{6}{|l|}{ TNF $\alpha$} \\
\hline Low CVD Risk & $0.83(0.42)$ & $0.95(.38)$ & \multirow[b]{2}{*}{0.546} & \multirow[b]{2}{*}{0.006} & \multirow[b]{2}{*}{0.320} \\
\hline $\begin{array}{l}\text { Elevated CVD } \\
\text { Risk }\end{array}$ & $1.55(2.45)$ & $1.27(.88)$ & & & \\
\hline \multicolumn{6}{|l|}{ Leptin } \\
\hline Low CVD Risk & $\begin{array}{c}7179.27 \\
(4087.90) \\
\end{array}$ & $\begin{array}{r}7946.64 \\
(5780.87) \\
\end{array}$ & \multirow{2}{*}{0.177} & \multirow{2}{*}{0.023} & \multirow{2}{*}{0.138} \\
\hline $\begin{array}{l}\text { Elevated CVD } \\
\text { Risk }\end{array}$ & $\begin{array}{l}13730.65 \\
(9171.93) \\
\end{array}$ & $\begin{array}{c}11526.31 \\
(11708.94) \\
\end{array}$ & & & \\
\hline
\end{tabular}


Table 2. Cont.

\begin{tabular}{|c|c|c|c|c|c|}
\hline $\begin{array}{l}\text { Biomarker } \\
\text { (pg/mL) }\end{array}$ & $\begin{array}{l}\text { Robust } \\
(n=52)\end{array}$ & $\begin{array}{c}\text { Pre-frail } \\
(n=52)\end{array}$ & $\begin{array}{c}\text { Main Effect of } \\
\text { Pre-frailty } \\
(p \text {-value }) \neq \\
\end{array}$ & $\begin{array}{c}\text { Main Effect of } \\
\text { CVD Risk } \\
(p \text {-value }) \neq\end{array}$ & $\begin{array}{c}\text { Interaction Effect } \\
(p \text {-value }) \neq\end{array}$ \\
\hline \multicolumn{6}{|l|}{ OPG } \\
\hline Low CVD Risk & $\begin{array}{l}203.15 \\
(72.24)\end{array}$ & $\begin{array}{l}216.11 \\
(66.55)\end{array}$ & \multirow{2}{*}{0.069} & \multirow{2}{*}{0.151} & \multirow{2}{*}{0.311} \\
\hline $\begin{array}{l}\text { Elevated CVD } \\
\text { Risk }\end{array}$ & $\begin{array}{c}220.54 \\
(109.24) \\
\end{array}$ & $\begin{array}{c}366.81 \\
(570.78)\end{array}$ & & & \\
\hline \multicolumn{6}{|l|}{ OC } \\
\hline Low CVD Risk & $\begin{array}{c}9215.50 \\
(3723.66)\end{array}$ & $\begin{array}{c}9805 \\
(4801.35)\end{array}$ & \multirow{2}{*}{0.985} & \multirow{2}{*}{0.153} & \multirow{2}{*}{0.900} \\
\hline $\begin{array}{l}\text { Elevated CVD } \\
\text { Risk }\end{array}$ & $\begin{array}{c}8688.65 \\
(4758.53)\end{array}$ & $\begin{array}{c}8791.65 \\
(5299.55)\end{array}$ & & & \\
\hline \multicolumn{6}{|l|}{ OPN } \\
\hline Low CVD Risk & $\begin{array}{c}5373.76 \\
(4408.36)\end{array}$ & $\begin{array}{c}6339.46 \\
(2996.10)\end{array}$ & \multirow{2}{*}{0.361} & \multirow{2}{*}{0.755} & \multirow{2}{*}{0.218} \\
\hline $\begin{array}{l}\text { Elevated CVD } \\
\text { Risk }\end{array}$ & $\begin{array}{c}6521.58 \\
(4391.42) \\
\end{array}$ & $\begin{array}{c}6956.11 \\
(6994.28) \\
\end{array}$ & & & \\
\hline \multicolumn{6}{|l|}{ IL-1 $\beta$} \\
\hline Low CVD Risk & $\begin{array}{r}862.38 \\
(448.86) \\
\end{array}$ & $\begin{array}{r}767.30 \\
(443.73) \\
\end{array}$ & \multirow{2}{*}{0.669} & \multirow{2}{*}{0.132} & \multirow{2}{*}{0.812} \\
\hline $\begin{array}{l}\text { Elevated CVD } \\
\text { Risk }\end{array}$ & $\begin{array}{c}714.70 \\
(559.30)\end{array}$ & $\begin{array}{r}745.80 \\
(616.32) \\
\end{array}$ & & & \\
\hline \multicolumn{6}{|l|}{ FGF23 } \\
\hline Low CVD Risk & $28.74(9.83)$ & $29.54(9.18)$ & \multirow[b]{2}{*}{0.786} & \multirow[b]{2}{*}{0.167} & \multirow[b]{2}{*}{0.530} \\
\hline $\begin{array}{l}\text { Elevated CVD } \\
\text { Risk }\end{array}$ & $41.50(43.10)$ & 35.38 (30.73) & & & \\
\hline
\end{tabular}

Continuous variables expressed as mean $\mathrm{pg} / \mathrm{mL} \pm$ standard deviation and compared using two-way ANOVA. $\neq p$ values presented are based on log transformed data. DKK1, Dickkopf WNT signaling pathway inhibitor 1; IL-6, interleukin-6; TNFa, tumor necrosis factor a; OPG, osteoprotegrin; OC, osteocalcin; OPN, osteopontin; IL-1 $\beta$, interleukin-1 $\beta$; FGF23, fibroblast growth factor 23.

\section{DISCUSSION}

No differences in the concentrations of the assessed bone metabolism analytes were found in females who were pre-frail, compared to those who were robust, and no interaction effects were found between prefrailty and CVD risk status. Based on these findings, analytes involved in bone metabolism may not be useful biomarkers of pre-frailty.

Reductions in bone health may occur concomitantly with frailty [32] as frailty has been predictive of osteoporotic fractures [45]. There is some evidence to suggest changes to bone health in the earlier, pre-frail stage as reduced bone mineral density has been identified in pre-frail females [46], but this research was on a slightly older cohort (mean age $=70$ years). Prefrail males have been found to have reduced bone health compared to frail 
males, as assessed by quantitative ultrasound [33]. Though, the bone mineral density scans of these pre-frail males were not significantly different from the robust group, indicating only early changes to bone health [32]. We found no differences in the concentrations of bone metabolism analytes between pre-frail and robust females. This may be because pre-frailty is too early in frailty progression for changes in bone health to be detected with biomarkers associated with bone metabolism. As such, differences in the concentrations of bone metabolism analytes between these two groups may not be identifiable until later frailty stages. Markers of bone metabolism have been reported to be higher in females with established frailty [47]. Therefore, had this study utilized females who were frail instead of pre-frail and who were older, differences in the concentrations of bone metabolism analytes between groups might have been found. This finding could warrant the use of alternative biomarkers allowing for early identification and intervention prior to the onset of associated adverse health outcomes. Thus far, evidence suggests that interventions implemented in the earlier pre-frail stage are more likely to successfully slow or reverse frailty progression [48].

Although no differences were found in the concentrations of bone metabolism analytes based on pre-frailty, differences were found based on CVD risk status. IL-6, TNFa, and leptin were higher in females at elevated CVD risk, as compared to females at low CVD risk.

IL-6 is an inflammatory cytokine typically involved in the body's immune response [49]. IL-6 has a wide range of inflammatory effects throughout the body [50] and it is involved in bone metabolism [51]. IL-6 has been reported to stimulate the genesis of osteoclasts, multinucleated giant cells with the capacity to breakdown bone tissue [52]. Thus, increased inflammation is associated with reduced bone mass [53]. Increased inflammation is also implicated in the development of CVD [54] and frailty [55]. We identified higher levels of IL-6 in females at elevated CVD risk, however, there was no difference in IL-6 concentration between robust and pre-frail females. Despite this finding, increases in IL-6 have often been identified in pre-frail and frail individuals [56]. This discrepancy may have resulted from the large variations in IL-6 concentrations between groups which might have impacted our ability to identify higher levels of IL6 in pre-frail females. In relation to CVD, the higher levels of IL-6 found in females at elevated CVD risk status is supported by previous evidence identifying IL-6 as a biomarker of CVD [57].

TNFa is also an inflammatory cytokine with an important role in the immune response and has pleiotropic effects throughout the body [58]. Like IL-6, TNFa is able to induce osteoclastogenesis, leading to the destruction of bone tissue [59]. Additionally, TNFa is able to suppress the activity of osteoblasts, cells responsible for forming new bone [60], further reducing bone health. As such, this inflammatory cytokine is thought to be associated with altered bone metabolism [61]. TNFa has already been identified as a biomarker of CVD [62] and because of its link with 
inflammation, evidence also supports its use as a potential biomarker of frailty with higher levels often being present in pre-frail and frail individuals [56]. Higher levels of TNFa were identified in females at elevated CVD risk but frailty status did not influence TNFa concentration in our study participants. Again, this discrepancy may be due to large variations in the concentration of this cytokine between groups. Past research supports the finding of higher levels of TNFa found in individuals at elevated CVD risk [63], indicating the efficacy of this cytokine in CVD risk assessment.

Leptin is a hormone predominately synthesized and secreted by adipocytes [64]. Leptin regulates bodyweight and energy balance [65], yet also has a complex role in bone metabolism [66,67]. The specific effects of leptin on bone metabolism are difficult to summarize [68], though research suggests leptin is necessary for both the inhibition and stimulation of bone formation [69,70]. A relationship between leptin and CVD has been established [71] and the use of leptin as a biomarker of CVD is supported by clinical studies demonstrating increased concentration of leptin is predictive of cardiovascular events [72]. Additionally, leptin concentrations are higher in obesity and other metabolic disorders which predispose for the development of CVD [73]. Thus, the increase in leptin concentration present in females at elevated risk for CVD might result from the presence of metabolic risk factors for CVD in this group.

\section{Limitations}

Despite using results from a similarly aged cohort to calculate sample size for this study [44], large variations in the concentrations of bone metabolism analytes in the systemic concentration were found within groups. This variation may have impacted our ability to identify differences between groups. The specific cause of this variation is unclear, and improved methodological approaches are needed to address variability in the future [74]. The measured analytes, while selected for their involvement in bone metabolism, also play a variety of pleiotropic roles throughout the body, such as the well-known roles of IL-6 and TNFa in inflammation [49,58]. This makes conclusively stating which pathophysiological processes connect the studied analytes to outcomes like pre-frailty or elevated CVD risk difficult to ascertain. Further, the collection of bone mineral density measures and information on potential hormone replacement therapies in the females of this cohort could have provided additional information on the bone health of the participants, which may have assisted in explaining why the bone metabolism analytes were not found to be effective biomarkers of pre-frailty.

\section{Future Directions}

There is an increasing need to identify and validate biomarkers of prefrailty and frailty as current identification is based on specific criteria which can sometimes be inconsistent [75]. While the measurement of bone 
metabolism analytes is effective in the monitoring of conditions like osteoporosis [76], bone metabolism analytes may not be useful biomarkers of pre-frailty as reductions in bone health may only be evident later in the frailty progression of most females. Additional research is necessary to (1) identify biomarkers of pre-frailty; (2) define the physiological ranges of these biomarkers; (3) identify the optimal method of assessing established biomarkers; and (4) examine the underlying pathophysiology connecting said biomarkers to frailty progression in more detail.

These findings will support the development of novel biomarker-based methods of pre-frailty and CVD risk assessment. The identification of effective biomarkers of pre-frailty may be used to identify potential physiological dysfunction, facilitate early intervention, and lead to the development of therapeutic strategies [77]. Promising biomarkers of prefrailty and CVD may be identified in our cohort in 2022, following the completion of a 5-year follow up period [39].

\section{CONCLUSIONS}

No differences were found for the concentrations of any bone metabolism analytes based on pre-frailty status, nor were any interaction effects between pre-frailty and CVD risk. It is possible these females were too early in the progression of frailty to have developed reductions in bone health that were detectable using biomarkers of bone metabolism. Concentrations of IL-6, TNFa, and leptin were found to be higher in females who were at elevated risk of developing CVD, as compared to females at low risk for developing CVD. This research suggests these cytokines involved in bone metabolism may act as potential biomarkers of CVD risk; however, it did not identify potential biomarkers of pre-frailty in middle-aged and older females.

\section{AUTHOR CONTRIBUTIONS}

TAD and KFB were involved in conception and design of the research. TAD and KFB obtained ethics approval. KFB, CJO, LAT, and TAD drafted the manuscript. All authors edited and revised the manuscript. All authors approved the final version of the manuscript. CJO performed data analysis. BMH provided statistical support.

\section{CONFLICTS OF INTEREST}

The authors declare no conflicting interests.

\section{FUNDING}

This study was financially supported by an operating grant from the St. Boniface Hospital Foundation, Winnipeg, Manitoba, Canada. KFB is supported by a Frederick Banting and Charles Best Canada Graduate Scholarship-CIHR Doctoral Award. CJO is supported by a Frederick 
Banting and Charles Best Canada Graduate Scholarship-CIHR Master's Award.

\section{REFERENCES}

1. Statistics Canada. Canada's population estimates: Age and sex, July 1, 2018. Available from: $\quad \underline{\text { https://www150.statcan.gc.ca/n1/en/daily- }}$ quotidien/190125/dq190125a-eng.pdf?st=7PJeGKWj. Accessed 2020 Oct 15.

2. Seniors. Available from: https://www150.statcan.gc.ca/n1/pub/11-402x/2011000/chap/seniors-aines/seniors-aines-eng.htm. Accessed 2020 Oct 15.

3. Kehler DS, Ferguson T, Stammers AN, Bohm C, Arora RC, Duhamel TA, et al. Prevalence of frailty in Canadians 18-79 years old in the Canadian Health Measures Survey. BMC Geriatr. 2017;17(1):28.

4. North BJ, Sinclair DA. The Intersection Between Aging and Cardiovascular Disease. Circ Res. 2012 Apr 13;110(8):1097-108.

5. Bergman H, Ferrucci L, Guralnik J, Hogan DB, Hummel S, Karunananthan S, et al. Frailty: An Emerging Research and Clinical Paradigm-Issues and Controversies. J Gerontol A Biol Sci Med Sci. 2007;62(7):731-7.

6. Fried LP, Tangen CM, Walston J, Newman AB, Hirsch C, Gottdiener J, et al. Frailty in older adults: evidence for a phenotype. J Gerontol A Biol Sci Med Sci. 2001 Mar;56(3):M146-56.

7. Lang P-O, Michel J-P, Zekry D. Frailty syndrome: a transitional state in a dynamic process. Gerontology. 2009;55(5):539-49.

8. Hanlon P, Nicholl BI, Jani BD, Lee D, McQueenie R, Mair FS. Frailty and prefrailty in middle-aged and older adults and its association with multimorbidity and mortality: a prospective analysis of 493737 UK Biobank participants. Lancet Public Health. 2018;3(7):e323-32.

9. Afilalo J, Karunananthan S, Eisenberg MJ, Alexander KP, Bergman H. Role of frailty in patients with cardiovascular disease. Am J Cardiol. 2009;103(11):1616-21.

10. Ferrucci L, Fabbri E. Inflammageing: chronic inflammation in ageing, cardiovascular disease, and frailty. Nat Rev Cardiol. 2018;15(9):505-22.

11. Flint K. Which came first, the frailty or the heart disease?: exploring the vicious cycle. J Am Coll Cardiol. 2015;65(10):984-6.

12. Farooqi MAM, Gerstein H, Yusuf S, Leong DP. Accumulation of Deficits as a Key Risk Factor for Cardiovascular Morbidity and Mortality: A Pooled Analysis of 154000 Individuals. J Am Heart Assoc. 2020;9(3):e014686.

13. Veronese N, Cereda E, Stubbs B, Solmi M, Luchini C, Manzato E, et al. Risk of cardiovascular disease morbidity and mortality in frail and pre-frail older adults: Results from a meta-analysis and exploratory meta-regression analysis. Ageing Res Rev. 2017;35:63-73.

14. Sergi G, Veronese N, Fontana L, De Rui M, Bolzetta F, Zambon S, et al. Prefrailty and risk of cardiovascular disease in elderly men and women: the Pro.V.A. study. J Am Coll Cardiol. 2015;65(10):976-83.

15. Boreskie KF, Rose AV, Hay JL, Kehler DS, Costa EC, Moffatt TL, et al. Frailty status and cardiovascular disease risk profile in middle-aged and older females. Exp Gerontol. 2020 Aug 16;140:111061. 
16. Gale CR, Cooper C, Sayer AA. Framingham cardiovascular disease risk scores and incident frailty: the English longitudinal study of ageing. Age Dordr Neth. 2014;36(4):9692.

17. Mitnitski A, Collerton J, Martin-Ruiz C, Jagger C, von Zglinicki T, Rockwood K, et al. Age-related frailty and its association with biological markers of ageing. BMC Med. 2015;13:161.

18. Lau ES, Paniagua SM, Guseh JS, Bhambhani V, Zanni MV, Courchesne P, et al. Sex Differences in Circulating Biomarkers of Cardiovascular Disease. J Am Coll Cardiol. 2019;74(12):1543-53.

19. Collerton J, Martin-Ruiz C, Davies K, Hilkens CM, Isaacs J, Kolenda C, et al. Frailty and the role of inflammation, immunosenescence and cellular ageing in the very old: Cross-sectional findings from the Newcastle 85+ Study. Mech Ageing Dev. 2012;133(6):456-66.

20. Soysal P, Arik F, Smith L, Jackson SE, Isik AT. Inflammation, Frailty and Cardiovascular Disease. Adv Exp Med Biol. 2020;1216:55-64.

21. Streeten EA. Bone as a classic endocrine organ: Interactions with non-bone tissues. Rev Endocr Metab Disord. 2015;16(2):77-8.

22. Datta HK, Ng WF, Walker JA, Tuck SP, Varanasi SS. The cell biology of bone metabolism. J Clin Pathol. 2008;61(5):577-87.

23. Zaidi M, Yuen T, Sun L, Rosen CJ. Regulation of Skeletal Homeostasis. Endocr Rev. 2018;39(5):701-18.

24. Severinsen MCK, Pedersen BK. Muscle-organ crosstalk: the emerging roles of myokines. Endocr Rev. 2020 May 11;41(4):594-609.

25. Colaianni G, Storlino G, Sanesi L, Colucci S, Grano M. Myokines and Osteokines in the Pathogenesis of Muscle and Bone Diseases. Curr Osteoporos Rep. 2020 Jun 8;18:401-7.

26. Li G, Zhang L, Wang D, AIQudsy L, Jiang JX, Xu H, et al. Muscle-bone crosstalk and potential therapies for sarco-osteoporosis. J Cell Biochem. 2019 May 20;120(9):14262-73.

27. Greco EA, Pietschmann P, Migliaccio S. Osteoporosis and Sarcopenia Increase Frailty Syndrome in the Elderly. Front Endocrinol. 2019;10:255.

28. Calvani R, Marini F, Cesari M, Tosato M, Picca A, Anker SD, et al. Biomarkers for physical frailty and sarcopenia. Aging Clin Exp Res. 2017;29(1):29-34.

29. van den Bergh JP, van Geel TA, Geusens PP. Osteoporosis, frailty and fracture: implications for case finding and therapy. Nat Rev Rheumatol. 2012;8(3):163-72.

30. Li G, Thabane L, Papaioannou A, Ioannidis G, Levine MAH, Adachi JD. An overview of osteoporosis and frailty in the elderly. BMC Musculoskelet Disord. 2017;18(1):46.

31. Ecss A, Ecss A. Association of Bone Mineral Density with Frailty, Pre-Frailty, and Osteoporosis in Community-Dwelling Elderly: A Prospective Study. Available from: https://clinmedjournals.org/articles/jgmg/journal-of-geriatricmedicine-and-gerontology-jgmg-3-033.php?jid=jgmg. Accessed 2020 Oct 15.

32. Cook MJ, Oldroyd A, Pye SR, Ward KA, Gielen E, Ravindrarajah R, et al. Frailty and bone health in European men. Age Ageing. 2017;46(4):635-41. 
33. Warburton DE, Nicol CW, Gatto SN, Bredin SS. Cardiovascular disease and osteoporosis: Balancing risk management. Vasc Health Risk Manag. 2007;3(5):673-89.

34. McFarlane SI, Muniyappa R, Shin JJ, Bahtiyar G, Sowers JR. Osteoporosis and cardiovascular disease: brittle bones and boned arteries, is there a link? Endocrine. 2004;23(1):1-10.

35. Jackson RD, Mysiw WJ. Insights into the epidemiology of postmenopausal osteoporosis: the Women's Health Initiative. Semin Reprod Med. 2014;32(6):454-62.

36. Norris CM, Yip CYY, Nerenberg KA, Clavel M-A, Pacheco C, Foulds HJA, Hardy $\mathrm{M}$, et al. State of the Science in Women's Cardiovascular Disease: A Canadian Perspective on the Influence of Sex and Gender. J Am Heart Assoc. 2020;9(4):e015634.

37. Eastell R, Szulc P. Use of bone turnover markers in postmenopausal osteoporosis. Lancet Diabetes Endocrinol. 2017;5(11):908-23.

38. STROBE Statement: Home. Available from: https://www.strobestatement.org/index.php?id=strobe-home. Accessed 2020 Oct 15.

39. Boreskie KF, Kehler DS, Costa EC, Cortez PC, Berkowitz I, Hamm NC, et al. Protocol for the HAPPY Hearts study: cardiovascular screening for the early detection of future adverse cardiovascular outcomes in middle-aged and older women: a prospective, observational cohort study. BMJ Open. 2017;7(11):e018249.

40. Boreskie KF, Kehler DS, Costa EC, Hiebert BM, Hamm NC, Moffatt TL, et al. Standardization of the Fried frailty phenotype improves cardiovascular disease risk discrimination. Exp Gerontol. 2019;119:40-4.

41. Duprez DA, Cohn JN. Identifying early cardiovascular disease to target candidates for treatment. J Clin Hypertens Greenwich Conn. 2008;10(3):226-31.

42. D’Agostino RB, Vasan RS, Pencina MJ, Wolf PA, Cobain M, Massaro JM, et al. General cardiovascular risk profile for use in primary care: the Framingham Heart Study. Circulation. 2008;117(6):743-53.

43. MILLIPLEX MAP Human Bone Magnetic Bead Panel-Bone Metabolism Multiplex Assay. Available from: http://www.emdmillipore.com/CA/en/product/MILLIPLEX-MAP-Human-BoneMagnetic-Bead-Panel-Bone-Metabolism-Multiplex-Assay,MM NF-HBNMAG$\underline{51 \mathrm{~K}}$. Accessed 2020 Oct 15.

44. Cornish SM, Chilibeck PD. Alpha-linolenic acid supplementation and resistance training in older adults. Appl Physiol Nutr Metab. 2009;34(1):49-59.

45. Ensrud KE, Ewing SK, Taylor BC, Fink HA, Stone KL, Cauley JA, et al. Frailty and risk of falls, fracture, and mortality in older women: the study of osteoporotic fractures. J Gerontol A Biol Sci Med Sci. 2007;62(7):744-51.

46. Ecss A, Ecss A. Association of Bone Mineral Density with Frailty, Pre-Frailty, and Osteoporosis in Community-Dwelling Elderly: A Prospective Study. Available from: https://clinmedjournals.org/articles/jgmg/journal-of-geriatricmedicine-and-gerontology-jgmg-3-033.php?jid=jgmg. Accessed 2020 Oct 15.

47. Álvarez-Sánchez N, Álvarez-Ríos AI, Guerrero JM, García-García FJ, RodríguezMañas L, Cruz-Chamorro I, et al. Homocysteine levels are associated with bone 
resorption in pre-frail and frail Spanish women: The Toledo Study for Healthy Aging. Exp Gerontol. 2018 15;108:201-8.

48. Gené Huguet L, Navarro González M, Kostov B, Ortega Carmona M, Colungo Francia C, Carpallo Nieto M, et al. Pre Frail 80: Multifactorial Intervention to Prevent Progression of Pre-Frailty to Frailty in the Elderly. J Nutr Health Aging. 2018;22(10):1266-74.

49. Akdis M, Aab A, Altunbulakli C, Azkur K, Costa RA, Crameri R, et al. Interleukins (from IL-1 to IL-38), interferons, transforming growth factor $\beta$, and TNF-a: Receptors, functions, and roles in diseases. J Allergy Clin Immunol. 2016;138(4):984-1010.

50. Wolf J, Rose-John S, Garbers C. Interleukin-6 and its receptors: a highly regulated and dynamic system. Cytokine. 2014;70(1):11-20.

51. Yoshitake F, Itoh S, Narita H, Ishihara K, Ebisu S. Interleukin-6 Directly Inhibits Osteoclast Differentiation by Suppressing Receptor Activator of NF- $\kappa B$ Signaling Pathways. J Biol Chem. 2008;283(17):11535-40.

52. Lee S-H, Kim T-S, Choi Y, Lorenzo J. Osteoimmunology: cytokines and the skeletal system. BMB Rep. 2008;41(7):495-510.

53. Loi F, Córdova LA, Pajarinen J, Lin T, Yao Z, Goodman SB. Inflammation, Fracture and Bone Repair. Bone. 2016;86:119-30.

54. Fernández-Ruiz I. Immune system and cardiovascular disease. Nat Rev Cardiol. 2016;13(9):503.

55. Wilson D, Jackson T, Sapey E, Lord JM. Frailty and sarcopenia: The potential role of an aged immune system. Ageing Res Rev. 2017;36:1-10.

56. Soysal P, Stubbs B, Lucato P, Luchini C, Solmi M, Peluso R, et al. Inflammation and frailty in the elderly: A systematic review and meta-analysis. Ageing Res Rev. 2016;31:1-8.

57. Nishida H, Horio T, Suzuki Y, Iwashima Y, Tokudome T, Yoshihara F, et al. Interleukin-6 as an independent predictor of future cardiovascular events in high-risk Japanese patients: comparison with C-reactive protein. Cytokine. 2011;53(3):342-6.

58. Zelová H, Hošek J. TNF-a signalling and inflammation: interactions between old acquaintances. Inflamm Res. 2013;62(7):641-51.

59. Lam J, Takeshita S, Barker JE, Kanagawa O, Ross FP, Teitelbaum SL. TNF-alpha induces osteoclastogenesis by direct stimulation of macrophages exposed to permissive levels of RANK ligand. J Clin Invest. 2000;106(12):1481-8.

60. Lu X, Gilbert L, He X, Rubin J, Nanes MS. Transcriptional regulation of the osterix (Osx, Sp7) promoter by tumor necrosis factor identifies disparate effects of mitogen-activated protein kinase and NF kappa B pathways. J Biol Chem. 2006;281(10):6297-306.

61. Osta B, Benedetti G, Miossec P. Classical and Paradoxical Effects of TNF-a on Bone Homeostasis. Front Immunol. 2014;5:48.

62. Ferrari R. The role of TNF in cardiovascular disease. Pharmacol Res. 1999;40(2):97-105.

63. Prediction of coronary disease incidence by biomarkers of inflammation, oxidation, and metabolism. Sci Rep. 2018;8:3191. 
64. Kershaw EE, Flier JS. Adipose tissue as an endocrine organ. J Clin Endocrinol Metab. 2004 Jun;89(6):2548-56.

65. Rosenbaum M, Leibel RL. Role of leptin in energy homeostasis in humans. J Endocrinol. 2014;223(1):T83-96.

66. Upadhyay J, Farr OM, Mantzoros CS. The role of leptin in regulating bone metabolism. Metabolism. 2015;64(1):105-13.

67. Cirmanová V, Bayer M, Stárka L, Zajícková K. The effect of leptin on bone: an evolving concept of action. Physiol Res. 2008;57(Suppl 1):S143-51.

68. Isaia GC, D’Amelio P, Di Bella S, Tamone C. Is leptin the link between fat and bone mass? J Endocrinol Invest. 2005;28(10 Suppl):61-5.

69. Turner RT, Kalra SP, Wong CP, Philbrick KA, Lindenmaier LB, Boghossian S, et al. Peripheral Leptin Regulates Bone Formation. J Bone Miner Res. 2013;28(1):22-34

70. Ducy P, Amling M, Takeda S, Priemel M, Schilling AF, Beil FT, et al. Leptin inhibits bone formation through a hypothalamic relay: a central control of bone mass. Cell. 2000;100(2):197-207.

71. Koh KK, Park SM, Quon MJ. Leptin and Cardiovascular Disease. Circulation. 2008;117(25):3238-49.

72. Wallace AM, McMahon AD, Packard CJ, Kelly A, Shepherd J, Gaw A, et al. Plasma leptin and the risk of cardiovascular disease in the west of Scotland coronary prevention study (WOSCOPS). Circulation. 2001;104(25):3052-6.

73. Andrade-Oliveira V, Câmara NOS, Moraes-Vieira PM. Adipokines as Drug Targets in Diabetes and Underlying Disturbances. J Diabetes Res. 2015;2015:681612.

74. Shetty S, Kapoor N, Bondu JD, Thomas N, Paul TV. Bone turnover markers: Emerging tool in the management of osteoporosis. Indian J Endocrinol Metab. 2016;20(6):846-52.

75. Saedi AA, Feehan J, Phu S, Duque G. Current and emerging biomarkers of frailty in the elderly. Clin Interv Aging. 2019;14:389-98.

76. Greenblatt MB, Tsai JN, Wein MN. Bone Turnover Markers in the Diagnosis and Monitoring of Metabolic Bone Disease. Clin Chem. 2017;63(2):464-74.

77. Coelho-Junior HJ, Picca A, Calvani R, Uchida MC, Marzetti E. If my muscle could talk: Myokines as a biomarker of frailty. Exp Gerontol. 2019;127:110715.

How to cite this article:

Boreskie KF, Oldfield CJ, Thompson LA, Moffatt TL, Hiebert BM, Arora RC. Bone Metabolism Analytes as Biomarkers of Pre-Frailty and Cardiovascular Disease Risk in Females. Adv Geriatr Med Res. 2020;2(4):e200025. https://doi.org/10.20900/agmr20200025 